\title{
Behavioral Determinants of Successful Early Melanoma Detection
}

\author{
Role of Self and Physician Skin Examination
}

Susan M. Swetter, MD², Ricardo A. Pollitt, MD, PhD²; Timothy M. Johnson, MD ${ }^{3,4,5}$; Daniel R. Brooks, DSc, $\mathrm{MPH}^{6}$; and Alan C. Geller, RN, $\mathrm{MPH}^{7}$

BACKGROUND. Reduced melanoma mortality should result from an improved understanding of modifiable factors related to early detection. The authors of this report surveyed newly diagnosed patients to identify differences in prediagnosis behavioral and medical care factors associated with thinner versus thicker melanoma. METHODS. In total, 566 adults with invasive melanoma completed questionnaires within 3 months of diagnosis on demographics, health care access, skin self-examination (SSE), and physician skin examination (PSE) practices in the year before diagnosis. SSE was measured by use of a melanoma picture aid and routine examination of some/all body sites versus none. Patient-reported partial or full-body PSE also was assessed. Melanoma thickness was dichotomized at $1 \mathrm{~mm}$. RESULTS. Patients ranged in age from 18 years to 99 years, and $61 \%$ were men. The median tumor thickness was 1.25 $\mathrm{mm}$, and 321 tumors (57\%) were $>1 \mathrm{~mm}$ thick. Thinner tumors $(\leq 1 \mathrm{~mm})$ were associated with age $\leq 60$ years $(P=$ $.0002)$, women $(P=.0127)$, higher education level $(P=.0122)$, and physician discovery $(P \leq .0001)$. Patients who used a melanoma picture aid and performed routine SSE were more likely to have thinner tumors than those who did not (odds ratio [OR], 2.66; 95\% confidence interval [Cl], 1.48-4.80). Full-body PSE was associated with thinner tumors (OR, 2.51; 95\% Cl, 1.62-3.87), largely because of the effect of PSE in men aged $>60$ years (OR, $4.0995 \% \mathrm{Cl}$, 1.88-8.89). CONCLUSIONS. SSE and PSE were identified as complementary early detection strategies, particularly in men aged $>60$ years, in whom both partial and full-body PSE were associated with thinner tumors. Given the high rates of physician access, PSE may be a more practical approach for successful early detection in this subgroup with highest mortality. Cancer 2012;118:3725-34. (C) 2011 American Cancer Society.

KEYWORDS: melanoma, early detection of cancer, prevention and control, self-examination, screening.

\section{INTRODUCTION}

Known factors related to thinner versus thicker cutaneous melanomas at diagnosis involve characteristics related to the patient, tumor, and mode of discovery. Thinner tumors are associated with physician detection (vs detection by the patient or significant other), ${ }^{1-9}$ women, ${ }^{1,4,6,10-14}$ younger age, ${ }^{10-15}$ higher level of education ${ }^{6,8,14-16}$ and socioeconomic status, ${ }^{17-20}$ increased access to specialty care, ${ }^{2,5,6,9,21}$ presence of atypical nevi, ${ }^{4,8}$ and non-nodular or desmoplastic histologic subtypes. ${ }^{10-13,22-25}$ However, these factors have not been studied in combination with patient health behaviors and

Corresponding author: Susan M. Swetter, MD, Department of Dermatology/Cutaneous Oncology, Stanford University Medical Center and Cancer Institute, 900 Blake Wilbur Drive, W1013, Stanford, CA 94305-5356; Fax: (650) 496-2573; sswetter@stanford.edu

${ }^{1}$ Dermatology Service, Veterans Affairs Palo Alto Health Care System, Palo Alto, California; ${ }^{2}$ Department of Dermatology, Pigmented Lesion and Melanoma Program, Stanford University Medical Center and Cancer Institute, Stanford, California; ${ }^{3}$ Department of Dermatology, University of Michigan Medical School, Ann Arbor, Michigan; ${ }^{4}$ Department of Otolaryngology, University of Michigan Medical School, Ann Arbor, Michigan; ${ }^{5}$ Department of Surgery, University of Michigan Medical School, Ann Arbor, Michigan; ${ }^{6}$ Department of Epidemiology, Boston University School of Public Health, Boston, Massachusetts; ${ }^{7}$ Department of Society, Human Development, and Health, Harvard School of Public Health, Boston, Massachusetts

Ricardo A. Pollitt's current address: Department of Dermatology, University of California, San Francisco, San Francisco, California

We acknowledge Mitzi C. Rabe, RN, BSN, OCN for her role as study coordinator at the University of Michigan. We also thank the Melanoma Prevention Working Group for its valuable contributions to the initial study design and analysis.

The sponsor had no role in the design or conduct of the study; in the collection, analysis, or interpretation of data; or in the preparation, review, or approval of the article.

DOI: 10.1002/cncr.26707, Received: August 30, 2011; Revised: October 17, 2011; Accepted: October 21, 2011, Published online December 16, 2011 in Wiley Online Library (wileyonlinelibrary.com) 
practices (eg, skin self-examination [SSE] and health care use) and physician skin examination (PSE) during routine medical care, as a means to promote early detection of cutaneous melanoma.

We performed a multi-institutional assessment of prediagnosis behavioral and medical care/access factors in men and women aged $\geq 18$ years with newly diagnosed, cutaneous melanoma to identify differences associated with thinner versus thicker tumors. Our objective was to investigate the associations among self- and physician examination practices and thinner melanoma at diagnosis, to more effectively formulate clinical and public health strategies for early melanoma detection. We hypothesized that both PSE and SSE practices would result in the diagnosis of thinner tumors; that their effect would differ according to age, sex, and type of skin examination performed (full-body vs partial); and that regular health care access would result in earlier detection by increasing the opportunity for PSE.

\section{MATERIALS AND METHODS}

\section{Study Participants}

Approval for the study was obtained from the institutional review boards of Stanford University Medical Center (SUMC), Veterans Affairs Palo Alto Health Care System (VAPAHCS), and the University of Michigan (UM). Eligible, consecutive patients aged $\geq 18$ years with a recent diagnosis of invasive cutaneous melanoma were surveyed at SUMC/VAPAHCS, as previously described. ${ }^{26}$ Because of the high proportion of thin melanoma at UM, which evaluates a population-based sample representative of the state (concordant with the state registrar), all eligible patients with melanoma $>2 \mathrm{~mm}$ and a random sample of $33 \%$ of individuals with tumors $\leq 2 \mathrm{~mm}$ were surveyed. Patients were surveyed in the melanoma clinics from May 17, 2006 through March 31, 2009, within 3 months of diagnostic biopsy. Respondents were instructed in person to answer all questions for the 12 months before diagnosis, and there were reminders in multiple locations on the survey to reinforce this point.

\section{Skin Self-Examination Measures}

We used a previously published measurement of SSE incorporating the number of body sites examined (ranging from 1 to 13 sites) and the use of a picture aid illustrating a melanoma tumor. ${ }^{26}$ An earlier analysis of a subset of our study patients (321 of 566) that examined only the effect of SSE had demonstrated that routine inspection of at least some of the measured body areas and use of a melanoma picture aid were associated significantly with reduced tumor thickness, whereas the frequency of mole examination was not.

\section{Demographic Measures}

The data analyzed included patient demographics (age, sex, education level, race/ethnicity, marital/cohabitation status), previous melanoma and nonmelanoma skin cancer history, and family history of skin cancer. Nevus count and the presence of clinical atypical nevi (CAN) were assessed by the clinician at the initial melanoma visit. Age was dichotomized at age 60 years given increasing rates of thicker tumors and increased mortality among older individuals (especially men) ${ }^{20,27-29}$ and evidence suggesting differences in melanoma awareness and skin examination practices by age. ${ }^{10-15}$

\section{Physician Skin Examination Variables}

Health care use in the year before diagnosis was assessed by questions asking where patients usually went when sick or in need of health advice (physician's office/clinic/health center vs urgent care center/emergency room vs other), whether they had a physician whom they consulted regularly for routine care, how many times they visited a physician during this year, whether a physician examined their skin for cancer during any visits, and whether the physician examined the patient's whole skin or just a particular lesion. Patients who responded "do not know" were excluded from specific analyses.

\section{Outcome Measures}

The primary study outcome was melanoma tumor depth at diagnosis. Because nearly $75 \%$ of fatal melanomas are associated with lesions thicker than $1 \mathrm{~mm},{ }^{30}$ this tumor cutoff point was used. We considered analyzing tumor thickness as a continuous outcome variable; however, this required $\log$ transformation to correct for the rightskewed distribution of melanoma thickness and the presentation of data with a geometric mean thickness, ${ }^{26}$ which are not easily interpretable.

\section{Statistical Analysis}

We used chi-square statistics to assess associations and conducted multivariable logistic regression analyses to assess the effects of various patient characteristics on melanoma tumor thickness at diagnosis. The odds ratio (OR) and $95 \%$ confidence interval $(\mathrm{CI})$ for having a thinner 
( $\leq 1 \mathrm{~mm}$ thick) tumor was calculated for different levels of each patient measure compared with a reference level. Decisions to include covariates as confounders in the models were based on a $10 \%$ change in the size of the independent variable's beta parameter upon inclusion of the covariate. The potential confounders examined included age, sex, race/ethnicity, education level, nevus count, and histologic subtype. Age, sex, and nevus count were retained in the models.

Statistical interaction between SSE measures and covariates was assessed by the significance of interaction terms (cutoff of $P<.2$ for consideration) that were entered into the models, and likelihood ratio tests were used to compare the model fit. ${ }^{31}$ Age, sex, education, histology, and the number of physician visits in the last year were examined as potential effect modifiers. Analyses were conducted using the SAS statistical software package (version 9.2; SAS Institute, Inc., Cary, NC). All tests of significance were 2-sided, and significance was defined as $P<.05$.

\section{RESULTS}

\section{Demographics}

In total, 566 of 719 eligible patients completed the questionnaire (79\%), including 225 from SUMC/VAPAHCS and 341 from UM. Refusals were related to patients' lack of interest/time, visual impairment, or anxiety related to diagnosis. Table 1 presents patient demographic information and tumor characteristics. Patients ranged in age from 18 years to 99 years (mean \pm standard deviation, $56.4 \pm 15.8$ years; median, 58 years). Ninety-four percent of patients reported this as their first melanoma, and 95\% denied having a prior nonmelanoma skin cancer.

\section{Tumor Characteristics}

The median tumor thickness was $1.25 \mathrm{~mm}$ (mean \pm standard deviation, $2.14 \pm 2.64 \mathrm{~mm}$ ), and 321 patients (57\%) had melanomas $>1 \mathrm{~mm}$ thick. The median tumor thickness for patients from SUMC/VAPAHCS and from UM was $1.2 \mathrm{~mm}$ and $1.3 \mathrm{~mm}$, respectively. Frequencies according to the American Joint Committee on Cancer 2009 tumor classification ${ }^{32}$ were $43 \%$ T1, 23\% T2, 21\% $\mathrm{T} 3$, and $13 \% \mathrm{~T} 4$. Thinner tumors were associated with superficial spreading $(P<.0001)$ and lentigo maligna $(P$ $=.012)$ histologic subtypes and with visible tumor pigmentation (vs amelanotic; $P=.0002$ ), absence of ulceration $(P \leq .0001)$, and extremity or trunk location compared with head and neck location $(P \leq .0001)$.

\section{Patient Characteristics}

Thinner tumors were associated with younger age $(\leq 60$ years; $P<.0001)$, women $(P=.0127)$, and a higher education level $(P=.0122)$ but not with marital/cohabitation status, prior skin cancer, or personal or family history of skin cancer. Thinner tumors were not associated with the presence of CAN, which was evident in $26 \%$ of respondents (OR, 1.06; 95\% CI, 0.65-1.72), or with an increasing number of moles (OR, 1.60; 95\% CI, 0.88-2.92 for patients with $>50$ moles vs $\leq 50$ moles). However, thinner tumors were associated with the patient previously being told by a physician that he/she had atypical/dysplastic nevi (OR, 1.88; 95\% CI, 1.15-3.06).

\section{Mode of Melanoma Discovery}

Most patients (53\%) self-detected melanoma compared with detection by physicians (19\%), spouse/partners $(16 \%)$, and family members/friends/other (11\%). Dermatologists detected 74 melanomas (13\%) compared with 35 melanomas $(6 \%)$ that were detected by primary care physicians. Self-detection was more common in younger patients (aged $\leq 60$ years) than in older patients ( $57 \%$ vs $46 \% ; P=.01$ ). Tumors discovered by a physician were significantly thinner than those discovered by the spouse/partner or by the patient (OR, 4.98; 95\% CI, 3.00-8.27 for physician detection vs patient detection). No significant difference was observed between discovery by a dermatologist (median thickness, $0.73 \mathrm{~mm}$ ) versus a nondermatologist $(0.72 \mathrm{~mm})$. There was no clear pattern of association between how long patients waited to see a physician for a skin examination after noting a suspicious skin lesion and thickness.

\section{Skin Self-Examination Practices and Thickness}

Twenty-four percent of patients reported use of a melanoma picture for SSE in the year before diagnosis, the use of which was associated with thinner tumors, as was routine self-examination of some/all of the body compared with none (OR, 1.98; 95\% CI, 1.24-3.18) (Table 2). The use of a melanoma picture aid in combination with routine SSE had an even stronger association with thinner tumors (OR, 2.66; 95\% CI, 1.48-4.80) compared with neither of these practices.

\section{Medical Access, Health Care Use, and Physician Skin Examination}

Greater than $95 \%$ of patients had health insurance, and $82 \%$ had a regular physician. Eighty-nine percent of 
Table 1. Frequencies of Sociodemographic Variables, Tumor Characteristics, and Nevus Count by Melanoma Tumor Depth at Diagnosis Dichotomized at 1 Millimeter Thickness $(N=566$

\begin{tabular}{|c|c|c|c|c|}
\hline \multirow[b]{2}{*}{ Variable } & \multicolumn{2}{|c|}{$\begin{array}{l}\text { Tumor Depth Dicho- } \\
\text { tomized at } 1 \mathrm{~mm} \text { : } \\
\text { Frequency }(\%)\end{array}$} & \multirow[b]{2}{*}{ Row Total } & \multirow[b]{2}{*}{$P$} \\
\hline & $\leq 1 \mathrm{~mm}$ & $>1 \mathrm{~mm}$ & & \\
\hline Age, y & & & & .0002 \\
\hline$\leq 40$ & $55(54)$ & $46(46)$ & 101 & \\
\hline $41-50$ & $48(47)$ & $54(53)$ & 102 & \\
\hline $51-60$ & $67(50)$ & $67(50)$ & 134 & \\
\hline $61-70$ & $46(39)$ & $72(61)$ & 118 & \\
\hline$\geq 71$ & $29(26)$ & $82(74)$ & 111 & \\
\hline Sex & & & & .0127 \\
\hline Men & $135(39)$ & $210(61)$ & 345 & \\
\hline Women & $110(50)$ & $111(50)$ & 221 & \\
\hline Education & & & & .0122 \\
\hline High school & $71(36)$ & $127(64)$ & 198 & \\
\hline Associates' degree & $40(41)$ & $57(59)$ & 97 & \\
\hline Four-year college & $134(49)$ & $137(51)$ & 271 & \\
\hline Race/ethnicity & & & & .1422 \\
\hline White & $237(44)$ & $302(56)$ & 539 & \\
\hline Nonwhite & $8(30)$ & $19(70)$ & 27 & \\
\hline No. of nevi & & & & .1590 \\
\hline $0-20$ & $156(42)$ & $218(58)$ & 374 & \\
\hline $20-50$ & $47(41)$ & $69(59)$ & 116 & \\
\hline $50-100$ & $31(55)$ & $25(45)$ & 56 & \\
\hline$\geq 100$ & $11(55)$ & $9(45)$ & 20 & \\
\hline Histologic subtype & & & & $<.0001$ \\
\hline SSM & $188(58)$ & $135(42)$ & 323 & \\
\hline NOD & $3(4)$ & $78(96)$ & 81 & \\
\hline LMM & $29(60)$ & $19(40)$ & 48 & \\
\hline ALM & $5(28)$ & $13(72)$ & 18 & \\
\hline Desmoplastic & $2(9)$ & $21(91)$ & 23 & \\
\hline Other/unclassified & $16(24)$ & $51(76)$ & 67 & \\
\hline Ulceration & & & & $<.0001$ \\
\hline Yes & $5(5)$ & $104(95)$ & 109 & \\
\hline No & $239(53)$ & $210(47)$ & 449 & \\
\hline Anatomic location & & & & $<.0001$ \\
\hline Head/neck & $32(26)$ & $91(74)$ & 123 & \\
\hline Trunk & $100(48)$ & 109 (52) & 209 & \\
\hline Extremity & $105(49)$ & $111(51)$ & 216 & \\
\hline
\end{tabular}

Abbreviations: ALM, acral lentiginous melanoma; LMM, lentigo maligna melanoma; NOD, nodular melanoma; SSM, superficial spreading melanoma.

patients reported at least 1 physician visit in the year before diagnosis, and $47 \%$ reported receiving a skin examination. Thinner tumors were associated with having 1) a regular health care location/facility when sick/needing advice (OR, 1.64; 95\% CI, 0.95-2.84), 2) a physician for routine care (OR, 1.64; 95\% CI, 1.03-2.62), 3) at least 1 physician visit (OR, 3.62; 95\% CI, 1.75-7.48), and 4) receiving a PSE for cancer (OR, 1.78; 95\% CI, 1.24-2.56) (Table 3). Overall, patients who received a full-body skin examination were significantly more likely to have thinner tumors (OR, 2.51; 95\% CI 1.62-3.87), whereas those who only had a particular lesion examined were not.

\section{Effect Modification by Age and by Sex}

A strong statistical interaction was observed by age (dichotomized at age 60 years) and sex for the associations between multiple measures of PSE and SSE and tumor thickness (Table 4). Patients aged $>60$ years who had a 
Table 2. Frequencies of Patient-Associated Behaviors/Practices Related to Skin Self-Examination With Odds Ratios and $95 \%$ Confidence Intervals That the Patient Had a Thinner Tumor $(\leq 1 \mathrm{~mm})$ at Diagnosis, Adjusted for Age, Sex, and Nevus Count

\begin{tabular}{|c|c|c|c|}
\hline Variable/Response & $\begin{array}{l}\text { No. of } \\
\text { Patients }\end{array}$ & $\begin{array}{l}\text { OR for Tumor } \\
\leq 1 \mathrm{~mm}\end{array}$ & $95 \% \mathrm{Cl}$ \\
\hline \multicolumn{4}{|l|}{ Ever used a melanoma picture to aid in $\mathrm{SSE}^{\mathrm{a}}$} \\
\hline Yes & 134 & 1.43 & \multirow[t]{2}{*}{$0.96-2.14$} \\
\hline No & 415 & Ref & \\
\hline \multicolumn{4}{|l|}{ How often patient carefully examined his/her moles ${ }^{a}$} \\
\hline Every 1-2 mo & 102 & 0.79 & $0.49-1.27$ \\
\hline Every $6 \mathrm{~m}$ & 94 & 1.18 & $0.72-1.93$ \\
\hline Every y & 94 & 1.00 & $0.61-1.64$ \\
\hline Never & 258 & Ref & \\
\hline \multicolumn{4}{|l|}{ Routinely examined skin on some/all of body ${ }^{a}$} \\
\hline Some/all & 465 & 1.98 & \multirow[t]{2}{*}{$1.24-3.18$} \\
\hline None & 101 & Ref & \\
\hline \multicolumn{4}{|c|}{ Routinely examined skin and/or ever used a picture aid in SSE } \\
\hline No picture aid but routinely examined some/all of skin & 326 & 2.17 & $1.28-3.66$ \\
\hline Used picture aid for routine SSE & 134 & 2.66 & \multirow[t]{2}{*}{$1.48-4.80$} \\
\hline No picture aid, did not routinely examine skin & 89 & Ref & \\
\hline \multicolumn{4}{|c|}{ When patient first became concerned about the skin lesion } \\
\hline Only at time of diagnosis & 171 & 1.91 & $0.97-3.77$ \\
\hline$\leq 1 \mathrm{y}$ & 340 & 0.65 & \multirow[t]{2}{*}{$0.35-1.23$} \\
\hline$>1$ y before diagnosis & 47 & Ref & \\
\hline \multicolumn{4}{|l|}{ Could easily see the lesion } \\
\hline Yes & 362 & 0.67 & \multirow[t]{2}{*}{$0.46-0.97$} \\
\hline No/do not know & 181 & Ref & \\
\hline \multicolumn{4}{|l|}{ Lesion color } \\
\hline Do not know & 62 & 1.29 & $0.73-2.27$ \\
\hline Pink & 76 & 0.44 & $0.25-0.76$ \\
\hline Skin colored & 32 & 0.22 & $0.08-0.58$ \\
\hline Pigmented & 368 & Ref & \\
\hline
\end{tabular}

Abbreviations: $\mathrm{Cl}$, confidence interval; OR, odds ratio; Ref, reference group; SSE, skin self-examination.

${ }^{\text {a }}$ SSE variables pertain to the year before melanoma diagnosis.

physician examine their skin for cancer had significantly higher odds of having a thinner tumor (OR, 3.11; 95\% CI, 1.65-5.86) compared with those who did not. In contrast, receipt of a PSE was not associated with thinner tumors among patients aged $<60$ years. Patients aged $>60$ years who received a full-body or partial PSE were more likely to have thinner tumors compared with those who did not (OR, 3.67 [95\% CI, 1.84-7.33] and OR, 2.93 [95\% CI, 1.29-6.67], respectively). Receipt of a full-body PSE was associated with thinner tumors (OR, 2.06; 95\% CI, 1.14-3.71) among younger patients, but receipt of a partial PSE was not.

The associations between PSE and thinner tumors also were much stronger among men who received a PSE for skin cancer, particularly a full-body PSE (OR, 3.13; 95\% CI, 1.82-5.39) versus a partial PSE (OR, 1.28; 95\% CI, 0.67-2.42), and among men who had a regular physi- cian (OR, 2.58; 95\% CI, 1.35-4.94). Women demonstrated no significant differences in the odds of having a thinner tumor by these variables.

Age and sex also had a strong interaction with 1 measure of SSE. Among patients aged $>60$ years, those who had used a melanoma picture to aid in SSE were more likely to have thinner tumors than those who did not (OR, 2.84; 95\% CI, 1.46-5.49). Among patients aged $\leq 60$ years, however, use of a melanoma picture aid and tumor thickness were unrelated. Men who had used a picture aid were more likely to have thinner tumors $(\mathrm{OR}$, 1.88; 95\% CI, 1.12-3.16), but no effect was observed among women. Age and sex were not strong effect modifiers of the association between the other SSE variables and tumor thickness. An assessment of interaction between age, sex, and certain variables (such as whether patients had consulted a physician in the last year) was not possible given sample size limitations. 
Table 3. Frequencies of Health Care-Associated Behaviors/Practices With Odds Ratios and 95\% Confidence Intervals That the Patient Had a Thinner Tumor ( $\leq 1 \mathrm{~mm})$ at Diagnosis, Adjusted for Age, Sex, and Nevus Count

\begin{tabular}{|c|c|c|c|}
\hline Variable/Response & $\begin{array}{l}\text { No. of } \\
\text { Patients }\end{array}$ & $\begin{array}{l}\text { OR for } \\
\text { Tumor } \leq 1 \mathrm{~mm}\end{array}$ & $95 \% \mathrm{Cl}$ \\
\hline \multicolumn{4}{|c|}{ Had a usual place to go when sick/needed health advice ${ }^{a}$} \\
\hline Other & 69 & Ref & \\
\hline Physician's office/clinic/health left & 488 & 1.64 & $0.95-2.84$ \\
\hline \multicolumn{4}{|l|}{ Had a physician for routine care ${ }^{a}$} \\
\hline No & 102 & Ref & \\
\hline Yes & 455 & 1.64 & $1.03-2.62$ \\
\hline \multicolumn{4}{|c|}{ Patient states they received a physician skin examination for cancer ${ }^{a}$} \\
\hline No & 289 & Ref & \\
\hline Yes & 258 & 1.78 & $1.24-2.56$ \\
\hline \multicolumn{4}{|c|}{ Type of skin examination performed by physician } \\
\hline None & 289 & Ref & \\
\hline Particular lesion & 93 & 1.16 & $0.71-1.90$ \\
\hline Whole skin & 147 & 2.51 & $1.62-3.87$ \\
\hline \multicolumn{4}{|c|}{ Who first noticed the mark that turned out to be melanoma? } \\
\hline You & 189 & Ref & \\
\hline Primary care physician/dermatologist & 109 & 4.98 & $3.00-8.27$ \\
\hline Spouse/family/friend & 78 & 1.32 & $0.85-2.05$ \\
\hline \multicolumn{4}{|c|}{ During the year before you found out you had melanoma, how many times did you visit a physician? } \\
\hline None & 48 & Ref & \\
\hline Once & 131 & 3.18 & $1.46-6.95$ \\
\hline 2-3 Times & 203 & 4.17 & $1.96-8.89$ \\
\hline$>3$ Times & 173 & 3.36 & $1.54-7.33$ \\
\hline \multicolumn{4}{|c|}{ During the year before you found out you had melanoma. did you visit a physician at least once? } \\
\hline No & 48 & Ref & \\
\hline Yes & 507 & 3.62 & $1.75-7.48$ \\
\hline
\end{tabular}

Abbreviations: $\mathrm{Cl}$, confidence interval; OR, odds ratio; Ref, reference group.

${ }^{a}$ Variables pertain to the year before melanoma diagnosis.

\section{Simultaneous Effect Modification by Age and Sex}

The presence of simultaneous effect modification by age and sex required stratifying the associations between the 3 variables addressed above and tumor thickness into 4 age/sex groups (Table 4). Among men aged $>60$ years, thinner tumors were strongly associated with having received a PSE for cancer (OR, 4.09; 95\% CI, 1.88-8.89). No significant associations between these variables and tumor depth were observed in younger men or in women of any age. These findings persisted when analyzed by histologic subtype and by the number of physician visits in the year before diagnosis.

\section{DISCUSSION}

Disproportionate melanoma incidence and mortality have been demonstrated in middle-aged and older men worldwide. $^{20,27,28,33}$ Compared with other demographic groups, older men tend to have thicker, more fatal mela- nomas ${ }^{10,13,15}$; more nodular melanoma ${ }^{11,22}$; and participate less frequently in mass screening efforts ${ }^{34}$ or in deliberate SSE. ${ }^{35}$ Our study demonstrated that thinner tumors in men aged $>60$ years were strongly associated with PSE, and this result supports the rigorous education of physicians regarding the benefits of full-body skin examination during routine care and of older men regarding the value of routine SSE and at least annual PSE.

Our results verify known associations with thinner melanoma at diagnosis, including younger age, female gender, location on anatomic sites other than the head or neck, patient perception of having CAN (as opposed to clinician assessment), higher educational level, visible tumor pigmentation, non-nodular or desmoplastic histologic subtype, and physician detection. More important, these results demonstrate the detection of thinner tumors in patients who, in the year before diagnosis, 1) regularly examined their own skin, 2) consulted a physician at least once, and 3) received full-body PSE for cancer, although examination of even a 
Table 4. Odds Ratios by Age and Sex: Frequencies of Variables With Odds Ratios and 95\%

Confidence Intervals That the Patient Had a Thinner Tumor $(\leq 1 \mathrm{~mm})$ at Diagnosis, Adjusted for

Age and Stratified According to Age $\leq 60$ Years Versus Age $>60$ Years, Sex, or Both Age and Sex

\section{Variable/Subgroup Response}

Stratified by age

Ever used melanoma picture to look at skin ${ }^{a}$

Aged $\leq 60$ y

No

Yes

Aged $>60$ y

No

Yes

Aged $\leq 60$

Aged

Yes

Aged $>60$ y

No

Yes

Type of skin examination performed by physician

Aged $\leq 60$ y

None

Particular lesion

Whole skin

Aged $>60 \mathrm{y}$

None

Particular lesion

Whole skin
No. of

Patients

246

84

169

50
OR for Tumor $\leq 1 \mathrm{~mm}(95 \% \mathrm{Cl})$

\section{Stratified by sex}

Ever used melanoma picture to look at skin ${ }^{a}$

Men

No

Yes

Women

No

Yes

Patient states they received a physician skin examination for cancer $^{\mathrm{a}}$

Men

No

Yes

163

Women

No

Yes
263

75

152

59
199

127

90

131

199

52

68

90

41

79

Type of skin examination performed by physician

Men

None

Particular lesion/unsure

Whole skin

Women

None

Particular lesion/unsure

Whole skin
172

126

86

163

58

102

126

35

45
Ref

$0.94(0.57-1.57)$

Ref

2.84 (1.46-5.49)

Ref

$1.23(0.79-1.99)$

Ref

$3.11(1.65-5.86)$

Ref

$0.68(0.36-1.28)$

$2.06(1.14-3.71)$

Ref

2.93 (1.29-6.67)

3.67 (1.84-7.33)

Ref

$1.88(1.12-3.16)$

Ref

$1.00(0.53-1.87)$

Ref

$2.06(1.29-3.28)$

Ref

$1.37(0.76-2.46)$

Ref

$1.28(0.67-2.42)$

$3.13(1.82-5.39)$

Ref

$1.05(0.48-2.32)$

$1.52(0.74-3.12)$

Stratified by age and sex

Patient states they received a physician skin examination for cancer ${ }^{\mathrm{a}}$ Men aged $\leq 60$ y

No

Yes

Women aged $\leq 60 \mathrm{y}$

No

Yes
104

72

95

55
Ref

$1.27(0.69-2.35)$

Ref

1.24 (0.62-2.49) 
Table 4. (Continued)

$\begin{array}{lll}\text { Variable/Subgroup Response } & \begin{array}{l}\text { No. of } \\ \text { Patients }\end{array} & \begin{array}{l}\text { OR for Tumor } \\ \leq 1 \mathbf{m m} \text { (95\% CI) }\end{array} \\ \begin{array}{l}\text { Men aged }>60 \text { y } \\ \text { No }\end{array} & 59 & \text { Ref } \\ \quad \text { Yes } \\ \text { Women aged }>60 \text { y } \\ \quad \text { No } \\ \text { Yes }\end{array}$

Abbreviations: $\mathrm{Cl}$, confidence interval; OR, odds ratio; Ref, reference group; SSE, skin self-examination

${ }^{a}$ Variables pertain to the year before melanoma diagnosis.

particular lesion was beneficial for older adults. It is noteworthy that the advantage of PSE was limited to men aged $>60$ years, who had 4 times the odds of a thinner tumor than older men who did not receive a PSE.

Middle-aged and older men comprise nearly half of all melanoma deaths, but only $16 \%$ of US men in this subgroup report ever receiving a physician screening. ${ }^{36,37}$ The importance of having regular access to medical care is highlighted by the finding that $33 \%$ of study patients who reported having a usual location for medical care and a regular physician for routine care received full-body PSE compared with only $11 \%$ of those who did not, although more frequent visits did not increase the odds of having a thinner tumor. SSE practices, as measured by the use of a melanoma picture aid and routine examination of some or all of the body, also significantly increased the odds of having a thinner melanoma, although this effect was limited to men and to older patients.

The reasons for the lack of impact of SSE and PSE on tumor thickness in men aged $\leq 60$ years or in women regardless of age are not clear, but different risks for melanoma and health surveillance behaviors/practices may play a part. In general, older men have a higher risk of developing melanoma and also participate less effectively in their health matters than younger men and women. Therefore, older men who undergo regular PSE may receive the greatest benefit from this practice. Conversely, physicians of older men may be more cognizant of the higher incidence and mortality, less frequent SSE practices, and thicker histologic subtypes in this subgroup and, thus, may perform PSEs more vigilantly. Younger patients tend to self-detect melanoma more than older patients ${ }^{14}$ ( $57 \%$ vs $46 \%$, respectively, in our study), typically have thinner tumors, and may not require the same frequency of PSE as older men.

The strongest evidence to date for the increased diagnosis of thinner tumors with physician skin screening was reported in a population-based case-control study of Queensland residents ages 20 to 75 years who had histologically confirmed, first primary, invasive melanoma. ${ }^{38}$ Wholebody clinical skin examination by a physician 3 years before diagnosis was associated with a $32 \%$ increased odds of having a $\mathrm{T} 1(\leq 1 \mathrm{~mm})$ melanoma at diagnosis. In addition, a screening program that was initiated at the Lawrence Livermore National Laboratory and conducted between 1984 and 1996 demonstrated that increased melanoma education, self-examination, and opportunity for PSE resulted in a reduction in crude incidence of thicker melanomas, although the study population was highly motivated. ${ }^{39}$ Whereas the published data in support of the association of SSE on melanoma thickness ${ }^{26,40}$ are less robust than those in support of PSE, our findings suggest that patient education and distribution of picture aids to increase SSE practices are justified. This is especially true among older men and is complementary to promoting PSE.

Our study inquired about PSE practices and health care use in the year before diagnosis, and many questions remain regarding why patients who had a PSE during that time had thinner tumors than those who did not, especially because only $19 \%$ of melanomas were detected by physicians. Without a proven survival benefit from PSE or melanoma screening itself, we can only speculate regarding the benefit of an earlier, nondiagnostic physician visit. It is possible that, at an earlier visit, the physician told the patient to follow a particular mole that subsequently changed or that the physician made note of a mole of concern that was not suspicious enough to warrant biopsy. Whether PSE overcomes patient delay in seeking medical attention for a suspicious lesion because of a lack of awareness or lower performance of SSE, or results in the detection of intrinsically less aggressive, slow-growing tumors (length bias) warrants further study.

Likewise, it is not clear why men aged $>60$ years, compared with younger men and all women in our study, 
reported nearly 1.5 to 3 more PSEs in the year before diagnosis. One study demonstrated that men aged $\geq 50$ years with a personal history of skin cancer were more likely to seek skin screening compared with women and younger men, although women were more likely to seek medical attention because of a particular lesion concerning for skin cancer. ${ }^{41}$ However, low rates of prior skin cancer and melanoma in our study cohort ( $6 \%$ and $5 \%$, respectively) do not support this explanation for increased PSEs in older men. Other possibilities include patient or physician recognition of higher melanoma risk, prompting of the physician by the patient or his spouse/partner in requesting a skin examination, or more suspicious but noncancerous lesions triggering routine PSE. Although the reasons for the stronger association of thinner tumors with PSE in older men do not appear to be a greater number of physician visits or differences in anatomic location, these issues, as well as a more detailed analysis of the role of physician detection in finding earlier nodular and desmoplastic subtypes, should be explored in future studies.

Study limitations include reliance on self-reports of health behaviors (SSE) and practices (health care use and PSE) and recall accuracy. Although all patients completed surveys within 3 months of diagnosis, potential over-reporting of health prevention practices is a possibility. Because the recall period for SSE and PSE practices extended up to 15 months (12 months before diagnosis coupled with a survey period of up to 3 months), there was likely some misclassification of these measures. In typical studies in which exposure is ascertained after diagnosis, differential misclassification of exposure (recall bias) can result in either exaggeration or dilution of the estimated association and is an important concern. However, in our study, all individuals had been diagnosed with melanoma, and the only difference was thickness, which makes it more likely that the main mechanism of misclassification would be nondifferential and, thus, would have underestimated the association. In addition, patient perception of who discovered the melanoma may vary, particularly if the patient notices a suspicious lesion but reports that the physician who performed the diagnostic biopsy discovered it. Strengths include the geographic diversity of the data collected, low rates of case refusal, short interval between diagnosis and completion of the survey, and contemporaneous clinician validation of nevus count and presence of clinical atypical nevi.

Because $72 \%$ of fatal melanomas are $>1 \mathrm{~mm}$ thick at diagnosis, ${ }^{30}$ reducing the burden of melanoma $>1 \mathrm{~mm}$ should be a goal to decrease mortality. To our knowledge, our study is the first to assess the effects of SSE and PSE by age and sex and to define the strong effect that physician screening has on the detection of thinner melanoma in older men. Our findings suggest that regular SSE and PSE potentially can surmount the higher mortality associated with this subgroup. Although both partial and whole-body examinations appear to be effective in older men, full-body PSE is preferable for the detection of melanoma in less visible but common sites (eg, back and scalp) that may be missed with the examination of a particular lesion.

Facilitating the performance of PSE in clinical practice requires overcoming both patient and physician barriers (eg, time constraints, competing comorbidities, and patient embarrassment). ${ }^{42}$ Routine PSE can be accomplished through enhanced physician training, physician awareness of higher risk for melanoma in the patient, and patient request for a full-body skin examination. Because so many individuals at risk of melanoma routinely consult physicians, ${ }^{43}$ improving physician training in full-body skin examination and increasing patient self-advocacy in requesting PSE are realistic strategies to improve early detection.

\section{FUNDING SOURCES}

This study was supported by Merck and Company, Inc. Dr. Pollitt's work was supported in part by the Stanford University Medical Scholars Research Program during his medical school tenure.

\section{CONFLICT OF INTEREST DISCLOSURES}

The authors made no disclosures.

\section{REFERENCES}

1. Epstein DS, Lange JR, Gruber SB, Mofid M, Koch SE. Is physician detection in associated with thinner melanomas? JAMA. 1999;281:640-643.

2. Richard MA, Grob JJ, Avril MR, et al. Delays in diagnosis and melanoma prognosis, II: the role of doctors. Int J Cancer. 2000;89:280-285.

3. Brady MS, Oliveria SA, Christos PF, et al. Patterns of detection in patients with cutaneous melanoma. Cancer. 2000;89:342-347.

4. Schwartz JL, Wang TS, Hamilton TA, Lowe L, Sondak VK, Johnson TM. Thin primary cutaneous melanoma: associated detection patterns, lesion characteristics, and patient characteristics. Cancer. 2002;95:1562-2568.

5. Fisher NM, Schaffer JV, Berwick M, Bolognia JL. Breslow depth of cutaneous melanoma: impact of factors related to surveillance of the skin, including prior skin biopsies and family history of melanoma. J Am Acad Dermatol. 2005;53:393-406.

6. Carli P, DeGiorgi VD, Palli D, et al. Dermatologist detection and skin self-examination are associated with thinner melanomas: results from a survey of the Italian Multidisciplinary Group on Melanoma. Arch Dermatol. 2003;139:607-612.

7. McPherson M, Elwood M, English DR, Baade PD, Youl $\mathrm{PH}$, Aitken JF. Presentation and detection of invasive 
melanoma in a high-risk population. J Am Acad Dermatol. 2006;54:783-792.

8. Swetter SM, Johnson TM, Miller DR, Layton CJ, Brooks KR, Geller AC. Melanoma in middle-aged and older men: a multi-institutional survey study of factors related to tumor thickness. Arch Dermatol. 2009;145:397-404.

9. Durbec F, Vitry F, Granel-Brocard F, et al. The role of circumstances of diagnosis and access to dermatological care in early diagnosis of cutaneous melanoma: a population-based study in France. Arch Dermatol. 2010;146:240-246.

10. Lasithiotakis K, Leiter U, Meier F, et al. Age and gender are significant independent predictors of survival in primary cutaneous melanoma. Cancer. 2008;112:1795-1804.

11. Liu W, Dowling JP, Murray WK, et al. Rate of growth in melanomas: characteristics and associations of rapidly growing melanomas. Arch Dermatol. 2006;142:1551-1558.

12. Chamberlain AJ, Fritschi L, Giles GC, Dowling JP, Kelly JW. Nodular type and older age as the most significant associations of thick melanoma in Victoria, Australia. Arch Dermatol. 2002;138:609-614.

13. Geller AC, Elwood M, Swetter SM, et al. Factors related to the presentation of thin and thick nodular melanoma from a population-base cancer registry in Queensland, Australia. Cancer. 2009; 115:1318-1327.

14. Richard MA, Grob JJ, Avril MF, et al. Delays in diagnosis and melanoma prognosis (I): the role of patients. Int J Cancer. 2000;89:271-279.

15. Youl PH, Baade PD, Parekh S, English D, Elwood M, Aitken JF. Association between melanoma thickness, clinical skin examination and socioeconomic status: results of a large populationbased study. Int J Cancer. 2010;128:2158-2165.

16. Baumert J, Plewig G, Volkenandt M, Schmid-Wendtner MH. Factors associated with high tumour thickness in patients with melanoma. Br J Dermatol. 2007;156:938-944.

17. Van Durme DJ, Ferrante JM, Pal N, Wathington D, Roetzheim RG, Gonzalez EC. Demographic predictors of melanoma stage at diagnosis. Arch Fam Med. 2000;9:606-611.

18. Ortiz CA, Goodwin JS, Freeman JL. The effect of socioeconomic factors on incidence, stage at diagnosis and survival of cutaneous melanoma. Med Sci Monit. 2005;11:163-172.

19. Zell JA, Cinar P, Mobashar M, Ziogas A, Meyskens FL Jr, Anton-Culver H. Survival for patients with invasive cutaneous melanoma among ethnic groups: the effects of socioeconomic status and treatment. J Clin Oncol. 2008;26:66-75.

20. Linos E, Swetter SM, Cockburn MG, Colditz GA, Clarke CA. Increasing burden of melanoma in the United States. $J$ Invest Dermatol. 2009;129:1666-1674.

21. Pennie ML, Soon SL, Risser JB, Veledar E, Culler SD, Chen SC. Melanoma outcomes for Medicare patients: association of stage and survival with detection by a dermatologist vs a nondermatologist. Arch Dermatol. 2007;143:488-494.

22. Bergenmar M, Ringbord U, Mansson Brahme E, Brandberg Y. Nodular histogenic type: the most significant factor for thick melanoma: implications for prevention. Melanoma Res. 1998;8:403-411.

23. Crocetti E, Carli P. Changes from mid-1980s to late 1990 s among clinical and demographic correlates of melanoma thickness. Eur J Dermatol. 2003;13:72-75.

24. Demierre MF, Chung C, Miller DR, Geller AC. Early detection of thick melanomas in the United States: beware of the nodular subtype. Arch Dermatol. 2005;141:745-750.

25. Warycha MA, Christos PJ, Mazumdar M, et al. Changes in the presentation of nodular and superficial spreading melanomas over 35 years. Cancer. 2008;113:3341-3348.
26. Pollitt RA, Geller AC, Brooks DR, Johnson TM, Park ER, Swetter SM. Efficacy of skin self-examination practices for early melanoma detection. Cancer Epidemiol Biomarkers Prev. 2009;18:3018-3023.

27. Geller AC, Miller DR, Annas GD, Demierre MF, Gilchrest BA, Koh HK. Melanoma incidence and mortality among US whites, 1969-1999. JAMA. 2002;288:1719-1720.

28. National Cancer Institute; Surveillance, Epidemiology, and End Results (SEER) Program. SEER Cancer Statistics Review, 1975-2007 [based on the November 2009 SEER data submission, posted to the SEER web site 2010]. Bethesda, MD: National Cancer Institute; 2010. Available at: http://seer.cancer.gov/csr/1975_2007/. Accessed March 30, 2011.

29. Cook MB, McGlynn K, Devesa S, Freedman DN, Anderson WF. Sex disparities in cancer mortality and survival. Cancer Epidemiol Biomarkers Prev. 2011;20:1-9.

30. Criscione VD, Weinstock MA. Melanoma thickness trends in the United States, 1988-2006. J Invest Dermtol. 2010;130:793-797.

31. Kleinbaum DG, Kupper LK, Muller KE, Nizam A. Applied Regression Analysis and Other Multivariable Methods. 3rd ed. Washington, DC: Brooks/Cole Publishing, 1998.

32. Balch CM, Gershenwald JE, Soong SJ, et al. Final version of 2009 AJCC melanoma staging and classification. J Clin Oncol. 2009;27:6199-6206.

33. Joose A, deVries E, Eckel R, et al. Gender differences in melanoma survival: female patients have a decreased risk of metastasis. J Invest Dermatol. 2011;131:719-726.

34. Geller AC, Zhang Z, Sober AJ, et al. The first 15 years of the American Academy of Dermatology skin cancer screening programs: 1985-1999. J Am Acad Dermatol. 2003;48:34-41.

35. Miller DR, Geller AC, Wyatt SW, et al. Melanoma awareness and self-examination practices: results of a United States survey. J Am Acad Dermatol. 1996;34:962-970.

36. National Center for Health Statistics. Health, United States, 2005. With Chartbook on Trends in the Health of Americans. Hyattsville, MD: National Center for Health Statistics; 2005.

37. Coups EJ, Geller AC, Weinstock MA, Heckman CJ, Manne SL. Prevalence and correlates of skin cancer screening among middle-aged and older white adults in the United States. Am J Med. 2010;123:439-445.

38. Aitken JF, Elwood M, Baade PD, Youl P, English D. Clinical whole-body skin examination reduced the incidence of thick melanomas. Int J Cancer. 2009;126:450-458.

39. Schneider JS, Moore DH , 2nd Mendelsohn ML. Screening program reduced melanoma mortality at the Lawrence Livermore National Laboratory, 1984 to 1996. J Am Acad Dermatol. 2008;58:741-749.

40. Berwick M, Begg CB, Fine JA, Fine JA, Roush GC, Barnhill RL. Screening for cutaneous melanoma by skin self examination. J Natl Cancer Inst. 1996;88:17-23.

41. Andrulonis R, Secrest AM, McGuire S, Geskin LJ, Ferris LK. The influence of age and sex on reasons for seeking and expected benefits of skin cancer screening. Arch Dermatol. 2010;146:1097-1102.

42. Oliveria SA, Heneghan MK, Cushman LF, Ughetta EA, Halpern AC. Skin cancer screening by dermatologists, family practitioners, and internists. Arch Dermatol. 2011;147: 39-44.

43. US Department of Health and Human Services, Centers for Disease Control and Prevention, National Center for Health Statistics. Health, United States 2010. DHHS Publ. No. 2011-1232. Hyattsville, MD: US Department of Health and Human Services; 2011. 